\title{
What is the Relationship between Benefit Conditionality and Mental Health? Evidence from the United States on TANF Policies
}

\author{
OWEN DAVIS \\ School of Social Policy, Sociology and Social Research (SSPSSR), University of Kent, \\ Canterbury, Kent, CT2 7NZ \\ email: od60@kent.ac.uk
}

\begin{abstract}
This article provides new evidence on the relationship between benefit conditionality and mental health. Using data on Temporary Assistance for Needy Families policies (TANF) the main form of poverty relief in the United States - it explores whether the mental health of low-educated single mothers varies according to the stringency of conditionality requirements attached to receipt of benefit. Specifically, the article combines state-level data on sanctioning practices, work requirements and welfare-to-work spending with health data from the Behavioral Risk Factor Surveillance System and evaluates the impact of conditionality on mental health over a fifteen-year period (2000 to 2015). It finds that states that have harsher sanctions, stricter job search requirements and higher expenditure on welfare-to-work policies, have worse mental health among low-educated single mothers. There is also evidence that between-wave increases in the stringency of conditionality requirements are associated with deteriorations in mental health among the recipient population. It is suggested that these findings may reflect an overall effect of 'intensive conditionality', rather than of the individual variables per se. The article ends by considering the wider implications for policy and research.
\end{abstract}

\section{Introduction}

Temporary Assistance for Needy Families (TANF) is the main safety net in US social policy that is targeted mainly at single mothers. It replaced Aid for Dependent Families with Children (AFDC) in 1996 through the Personal Responsibility and Work Opportunity Reconciliation Act (PRWORA), as part of President Clinton's pledge to 'end welfare as we know it'. The introduction of TANF was accompanied by new rules imposed by the federal government for states to increase conditionality and place time limits on the receipt of cash benefit, amongst other changes. This marked a departure from the entitlement-based AFDC that carried few conditions, provided that claimants met the eligibility requirements (Page and Larner, 1997).

A central aspect of the PRWORA reform was that requirements were placed on states for recipients to engage in work-related activities, with the necessary 
imposition of benefit sanctions for non-compliance. Three federal requirements were placed on states to apply to all work-eligible TANF recipients: Employability Assessments, Work within Two Years and Sanctions for Failure to Comply with Work Requirements (Falk, 2012). For each working age adult or teen recipient, the 1996 law required states to assess their skills, employability and 'work-readiness' within 90 days of a claim being made. Similarly, the 'Work within Two Years' legislation required states to engage all work-eligible recipients in work-related activities within two years. Benefit sanctions were to be applied for any family member that did not participate in work-related activities without 'good cause'. States were given discretion around what constituted 'good cause' and the severity of sanctions (2012: 18).

While the PRWORA imposed certain rules on states for the use of federal funds, it also devolved greater autonomy around sanctions, work-related activities and other behavioural requirements. These changes greatly increased the variability of TANF policies across states (see, for example, De Jong et al., 2006; Meyers et al., 2001). This led to new research efforts by scholars of US social policy to develop formal typologies of states in terms of their TANF practices (see Fender et al., 2002 for a full review). Yet this literature is limited and now quite dated. In particular, there is very little published work on the recent context of TANF and the longer-term consequences of the PRWORA and the shift towards more intensive conditionality practices.

One of the contributions of this article is to update and expand this evidence. It provides the first in-depth analysis of variation across states and over time (2000-2015) in the development of conditionality practices linked with receipt of TANF cash benefits. While this is one aim of the article, it is not the central objective. The main purpose is to use these data to understand more about the impacts of TANF conditionality on mental health over this same period. It responds to a growing interest among social policy academics in the wider consequences of benefit conditionality for health, wellbeing and social rights, especially among disadvantaged groups (Dean, 2003; Garthwaite et al., 2014; Reeves and Loopstra, 2016; Shutes, 2016; Geiger, 2017).

\section{Work-related conditionality in advanced welfare states}

While the central interest of this article is in the impacts of benefit conditionality on mental health, it contributes to a broader literature on the implications of shifts towards increased conditionality across many advanced welfare states (e.g. Clasen and Clegg, 2007; Dwyer and Wright, 2014; Kilkey, 2017; Shutes, 2016). In an important addition to these debates, Clasen and Clegg (2007) define conditionality using a three-fold classification: conditions of category, circumstance and conduct. The first two of these are concerned with the eligibility criteria for receipt of benefit. Conditions of category are the definitions of need that provide the basic qualifying criteria for benefits, 
i.e. 'unemployed', 'elderly' or 'disabled'. Yet in many cases these conditions of eligibility do not automatically equate with entitlement and often individuals are required to meet further conditions of circumstance. The most obvious example of this is in relation to unemployment benefits and pensions. To qualify for either of these benefits, individuals are usually required to have worked a certain number of years, thus specific groups may not be eligible if their work history is incomplete. The first two of Clasen and Clegg's (2007) 'levels' of conditionality are analytically different from the third set of conditions ('conditions of conduct'), which are the requirements placed on benefit recipients after meeting the initial eligibility criteria. In most welfare states, the main 'conditions of conduct' are job search requirements and associated penalties for failure to meet these conditions. These conditions are the focus of this article.

There has been concern among social policy researchers that work-related 'conditions of conduct' may be ineffective or even harmful for certain groups. Nearly all of this research is from the United Kingdom (UK). For example, Dean (2003) argues that welfare-to-work requirements may be ill-suited to individuals that are particularly distant from the labour market. Based on evidence from 50 in-depth interviews with benefit recipients with multiple needs (including drugs, alcohol, homelessness), he found that welfare-to-work policies could (counter-productively) lead to self-blame which created further distance from paid work (2003: 445). For these groups, he suggests an alternative 'life-first' approach that prioritises work-life balance and the right to seek appropriate work above immediate return to formal employment (2003: 455-456). More recently, Reeves and Loopstra (2016) made a similar argument based on an analysis of the Annual Population Survey in which they found that single parents and disabled people (in the UK) were more likely to receive a benefit sanction than other groups. This, they argued, may be ineffective in helping these groups return-towork given that they may already have multiple barriers to paid employment (2003: 335-6). A recent report also raised concerns that homeless people in the UK were disproportionately likely to be sanctioned which could exacerbate homelessness and hinder the process of recovery (Beatty et al., 2015).

The emphasis of much of this prior research has been on the efficacy of conditionality and the implications for social rights (also see Shutes, 2016). Less research has considered the impact of such policies on the health and wellbeing of disadvantaged groups, yet this is an important question given that conditionality has often been justified with paternalistic aims of improving life outcomes (Mead, 1997). A notable exception to this is a longitudinal mixed-methods study by Garthwaite et al. (2014) where the authors investigated the health of sickness benefit recipients in the UK between 2009 and 2010, during a period of increased conditionality in the welfare system. The authors found no statistically significant change in the health of recipients over an 18-month period, despite an intensification in conditionality requirements (2014: 319). The data suggested 
that the health of recipients was poor, but stable, throughout this period and this was corroborated in 25 in-depth interviews. The results from this study therefore did not clearly show that intensifying conditionality had any effects on health. However, the authors concluded, based on the evidence of poor health among recipient populations, that conditionality should be implemented cautiously and with awareness of the multiple health needs of vulnerable populations (2014: 326). There is more concrete evidence of a negative impact of conditionality on mental health, in another article, which focused on the impacts of Work Capability Assessments on disabled people in the UK benefits system (Barr et al., 2016). Analysing the relationship between trends in reassessments for benefit eligibility and mental health between 2010 and 2013, these authors found that stringent conditionality was associated with increases in suicides, self-reported mental ill-health and prescriptions of antidepressants (Barr et al., 2016).

These two articles are the only identifiable research projects, to this author's knowledge, which have looked directly at the impact of work-related conditionality on health. Others have looked at related issues such as the effect on health of reductions in income for benefit recipients (Moffatt et al., 2015), or the relationship between labour market activation programmes and mental health (Carr and Chung, 2014; Niedzwiedz et al., 2016; Wulfgramm, 2011). In the US context, two articles have examined the health effects of the transition from AFDC to TANF in 1996 (Basu et al., 2016; Bitler et al., 2005), yet neither focused on specific aspects of TANF conditionality such as sanctions or job search requirements.

This article makes a number of concrete contributions to the existing literature. First, it uses data on TANF conditionality practices, which have not (to this author's knowledge) been used in any prior study. It exploits variation in policies across US states to show how the health impact of sanctions, job search and welfare-to-work varies according to the stringency of conditionality requirements. Second, it examines the impact of TANF conditionality on mental health over an extended period of time, using data on TANF policies covering a fifteen-year period (2000, 2005, 2010 and 2015). This enables stronger causal inference, as the cross-sectional analysis is supplemented by a research strategy that models the effect on health of changes in TANF policies. Third, the article uses subpopulation analysis to draw conclusions about the effects of TANF conditionality on low-educated single mothers. This has both substantive and methodological advantages. On the one hand, it enables the article to contribute towards the existing literature on the differential effects of conditionality for socially disadvantaged populations (Dean, 2003; Reeves and Loopstra, 2016; Shutes, 2016). Yet it also has pragmatic advantages. Recipient groups of TANF cash benefits are difficult to define as the characteristics of the TANF caseload have changed over time ${ }^{1}$. However, some elements have remained stable. For example, the vast majority of adult TANF recipients are women (e.g. 85.7 per cent in 2013) 
and in most cases these are single mothers with children (Falk, 2012: 5). Recipients also tend to be poor and either unemployed or in low-paid work (Falk, 2016: 8). Hence, it seems reasonable to look not only at single mothers but also those with the lowest human capital, as defined here by low educational attainment.

\section{State-level variables}

Temporary Assistance for Needy Families policies are operationalised using data from the Welfare Rules Database (WRD) and Federal TANF and State Financial Data, held by the Office of Family Assistance ${ }^{2}$. The three key variables are job search requirements, welfare-to-work spending and sanctions. Job search requirements are constructed using a binary variable based on whether or not states require job search at application as a condition of eligibility, taken from the WRD. Welfare-to-work spending is taken from TANF financial data. A per capita measure is calculated through dividing the total amount that each state spent in a fiscal year on welfare-to-work measures including 'subsidised employment', 'education and training' and 'additional work activities', by the average number of TANF recipients within the same fiscal year (see online Appendix, Figure A1).

State-level sanctioning practices are captured in data that is divided into two sections: initial sanction and most severe sanction, following the approach of others $^{3}$. The final operationalisation which is applied for each state and for the years 2000, 2005, 2010 and 2015 is as follows:

1. Most Lenient: Initial partial sanction less than 33 per cent of full entitlement, no progression to entire benefit sanction

2. Lenient: Initial partial sanction less than 33 per cent of full entitlement, delayed full sanction

3. Stringent: Initial partial sanction over 33 per cent of full entitlement, delayed full sanction

4. Most Stringent: Initial entire sanction or case closure

The analysis focuses on the difference between the 'most lenient' and 'most stringent' states as ambiguity between these categories is least. State-level control variables are included for maximum monthly benefits, GDP per capita, political and citizen ideology and unemployment rates. Maximum monthly benefits are an average monthly benefit for a family of three with no income, taken from the WRD. These values are conditioned on Purchasing Power Parities (PPPs) across the US states to account for differences in the cost of living. Gross Domestic Product per capita and unemployment rates were retrieved from the US Bureaux of Economic Affairs and Labor Statistics, respectively. Two control variables are also included to account for cultural and political differences across states: political and citizen ideology. These variables were originally designed by Berry et al. (1998) and remain widely used in political science and related disciplines to capture state-level differences in political ideology. 


\section{Individual-level variables}

The TANF data are merged using state and wave identifiers with individuallevel data from the 2000, 2005, 2010 and 2015 waves of the Behavioral Risk Factor Surveillance System (BRFSS). The BRFSS is the largest telephone-based survey in the world. It is an annually repeated cross-sectional survey covering all 50 US states and the District of Columbia. On average, more than 400,000 people complete the BRFSS annually. Median response rates compare favourably with other telephone surveys ${ }^{4}$ and are only fractionally lower than those of established cross-national surveys such as the European Social Survey ( 53 per cent in 2015).

The BRFSS contains one variable around mental health, which was the main outcome of interest in this article. The dependent variable is the 'number of days' that somebody reports mental ill-health. The variable is kept as continuous, following the approach of others (e.g. Basu et al., 2016) where a higher number indicates worse mental health, i.e. o represents o days of mental ill-health and 30 represents a full month. While this variable is less ideal than other validated measures of mental health (e.g. the Center for Epidemiological Studies Depression Scale), it is the only indicator of mental health available consistently within the BRFSS over the period in question. It has also been validated in one systematic review of studies related to the BRFSS (Pierannunzi et al., 2013).

Finally, the following individual-level predictor variables are included: loweducated single mother, age, marital status and ethnicity. The first of these low-educated single mothers - is an exposure variable of substantive interest. The other variables are used as controls. The BRFSS does not have a question around whether or not someone has children. The closest approximation to this is a question that asks how many children under the age of 16 live in the household. All women that live within a household with one or more children are considered parents. The variable for single mothers is then created by selecting unmarried/not cohabiting women with at least one child in the household. It is unfortunate that the BRFSS does not have a variable that directly ascertains whether someone is a parent. However, the generated variable for single mothers is a reasonable approximation, based on the same method as that of Basu et al. (2016).

This variable is further refined so that it represents only those single mothers with a low level of education. This is based on a question around the number of years of school completed. Following the recommended approach for operationalising education in the BRFSS codebook, a dummy variable is created where $1=$ single mothers that did not graduate from high school and $o$ $=$ all other mothers. Age is included as a standardised variable ( $\mathrm{z}$ values). Marital status is also made into a dummy, where $o=$ neither married nor a member of an unmarried couple and $1=$ married or a member of an unmarried couple. A variable is also included for race where $0=$ white and $1=$ non-white. In some ways it is not ideal to 'control out' the influence of race given our direct interest 
in the TANF recipient population, of whom nearly three-quarters are non-white (Falk, 2016: 6). However, it was not possible to stratify the population further into white and non-white low-educated single mothers due to small sample sizes. It should therefore be noted that the regression models show only the 'average' impact of TANF policies and may obscure any differential impacts between white and minority groups.

\section{Research hypothesis and statistical approach}

Based on prior research, the overarching hypothesis of this article is that states that have more stringent conditionality practices will tend to have worse mental health among low-educated single mothers, relative to other mothers. The reasons for this are threefold.

First, there is no convincing evidence that states with more intensive conditionality practices have lower unemployment rates (Rector and Youssef, 1999) ${ }^{5}$. Moreover, additional analyses conducted by this author (available upon request) confirmed that states with more stringent TANF conditionality policies did not have lower odds of self-reported unemployment among low-educated single mothers. Any expected health benefits of conditionality would be linked with better employment outcomes for recipient groups and this does not seem to be the case. Second, research from the UK and the US finds that, in general, those groups that are most likely to be at the receiving end of conditionality (particularly sanctions) already have considerable barriers to employment (Pavetti et al., 2003; Reeves and Loopstra, 2016). This research also shows that conditionality tends to be less effective at moving these groups towards the labour market. Third, the analysis by Garthwaite et al. (2014) suggested that vulnerable groups can experience considerable mental distress as a result of conditionality practices.

The article therefore tests the following research hypothesis:

States that invest more in welfare-to-work programmes, have stricter work requirements and more stringent sanctions will have a wider gap in mental health between low-educated single mothers and other mothers.

To do this it looks at the mental health gap between low-educated single mothers (the treatment group) and all other mothers (the control). With two minor exceptions, this follows the approach to evaluating the impact of PRWORA used by Basu et al. (2016) ${ }^{6}$. The key differences are that i) the treatment group are low-educated single mothers (for reasons previously outlined) and ii) women that are not mothers are excluded from the control group. The aim of the second point is to improve on the approach of Basu et al., by focusing on a control group that share more in common with the treatment population.

This meant that all observations for males, women that were not mothers and those of non-working age $(<18$ or $>65)$ were excluded. After merging all 
four BRFSS datasets, this left an effective sample of 559,267. Two modelling strategies were used. The first of these is ordinary linear regression, with clusterrobust standard errors. This 'cluster-robust' regression method represents only a minor modification on standard regression techniques. It allows us to account for the non-independence of predictor variables within models, due to likely similarities between individuals within states. The standard errors are more conservative, making it less likely that we will wrongly report a statistically significant (individual) effect due to contextual influences.

The second modelling procedure is fixed effects regression analysis. The purpose of this is to improve the causal claims that the article can make about the effect of TANF by allowing us to infer the impact on health of changes in TANF policies. By 'fixing' the effects of states through the inclusion of $\mathrm{N}-1$ state dummy variables, the regression models control for all time-invariant unobservable variables at the state level (Allison, 2009). This essentially isolates changes in any other state-level variables included in the models (e.g. TANF policies). Therefore, provided that other time-variant confounders are included in the model, then the Beta values for the policy variables should represent the effect of changes in these values or the 'average treatment effect' of a given area of TANF policies.

\section{Descriptive statistics}

Over four waves and fifty states there were 196 total non-missing observations. Thirty-four states had a 'very lenient' sanction at some point over the four years, while 78 had a 'very severe' sanction. Only 34.5 per cent required a job search at one point, while nearly two-thirds did not. On average, states spent $\$ 697$ on welfare-to-work programmes although there was substantial variance in this figure (Standard Deviation $=\$ 766.2$ ). These descriptive statistics are summarised in online Appendix Table A1.

There was evidence that states had overlap in their TANF conditionality practices (see online Appendix Figures A2 to A4). Specifically, there was a clear tendency for states that have job search requirements and stringent sanctions, to spend a greater amount on welfare-to-work programmes. Conversely, there was no strong evidence of a relationship between job search and sanctions. This early analysis suggests that states can be divided conceptually into two categories: those which combine positive and negative incentive structures to encourage and enforce labour market participation and those with weaker conditionality policies which have less of both positive and negative incentives.

\section{TANF trends 2000-2015}

The analysis in this article looks at both variation across states in TANF policies, and changes over time within states. To assess, descriptively, the extent to which the three TANF variables changed over time, we explore the percentage 


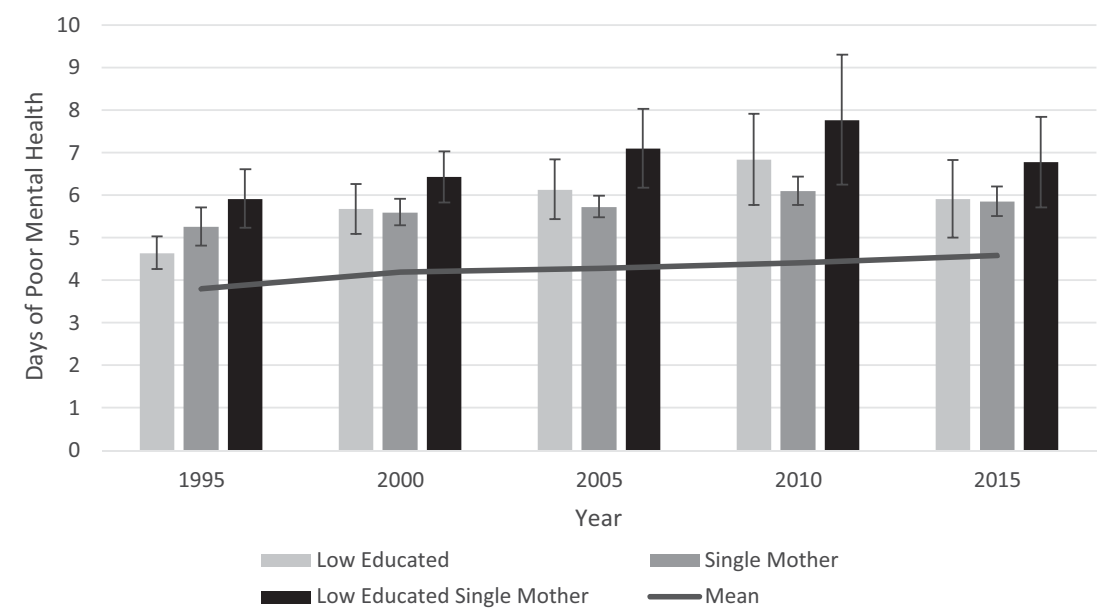

Figure 1. Trends in Mental Health by Education and Single Mother Status, BRFSS 1995-2015

of states that had no change, became more severe/stringent, more lenient or generous or whose policies did not exhibit a clear trajectory towards greater stringency or generosity (fluctuated) (see online Appendix, Table A2). Twentynine per cent of all states became more stringent in their sanctioning practices throughout this period. Three states (Arkansas, Indiana and Texas) even went from maximum leniency to maximum stringency in their sanctioning policies. No states became more lenient and only 6 per cent fluctuated, while 65 per cent of states stayed the same. For job search, the majority similarly stayed the same (61 per cent), while a more even balance became more stringent/lenient or fluctuated. For welfare-to-work spending, no states remained the same or became more stringent. One-third became more lenient, while two-thirds fluctuated.

Overall, this early analysis shows a general trend of tighter sanctions alongside greater investment in welfare-to-work. A large number of states remained fairly stable in their TANF policies, with the exception of welfare-to-work spending, which was highly variable across years.

\section{Trends in mental health}

The parallel interest of the article is in how these trends in TANF may have mattered for mental health. Figure 1 shows trends in mental health for loweducated people, single mothers and low-educated single mothers, compared with the mean. It includes the year 1995, before TANF was introduced, as data from the BRFSS extend back this far. For all population groups, there were indications that mental health worsened between 1995 and 2010, with a slight improvement between 2010 and 2015. The results show that being a single mother 
per se appears to have a (detrimental) impact on mental health of a similar magnitude to being low-educated. There appears to be a slight increase in mental ill-health for single mothers over the period which follows a similar gradient to that of the population at large (as indicated by the mean line). However, the graph suggests that low-educated single mothers do consistently worse than both loweducated people and (average) single mothers throughout the period. In short, there appears to be a 'double burden' of low education and single motherhood, although for low-educated single mothers the confidence intervals are wide due to smaller sample sizes and this is particularly the case in 2010.

In sum, these early bits of analysis suggest that i) both low education and single motherhood are associated with poor mental health ii) being both a single mother and low-educated is a high risk for poor mental health and this risk seems to have risen over time. The latter finding implies that changes in TANF provision may have had a mental health impact, as those women most likely to receive TANF are likely to be both single mothers and low-educated.

\section{Results}

The main analysis explores whether these descriptive trends reflect evidence of an effect of TANF policies on mental health. Table 1 presents the core results from a series of OLS (1-3) and OLS fixed effects (4) regression models that examine this. It shows the results from a series of interaction effects which model the differential effect of the three TANF policies' variables on the mental health of low-educated single mothers compared with other mothers. It also includes the remaining effect for low-educated single mothers under 'Individual' covariates. Models 1-3 include interaction effects for the three TANF conditionality variables. Model 4 then includes all these interaction effects, as well as state fixed effects.

All three of the coefficients for the TANF interaction effects have confidence intervals that are significantly different from zero, although in each case these confidence intervals are also wide, due to the reasonably small sample sizes $(\mathrm{N}=195)$. The coefficients for all three variables are positive and substantial, even in model 4 with full controls and fixed effects (although lower bounds of the confidence intervals suggest the effects may be small). For each of these policy areas there was also evidence that a between-wave increase in stringency/welfareto-work investment was associated with worse mental health, as shown by the fixed effects specification in model 4 .

To interpret these findings correctly, it is helpful to refer to the descriptive statistics, presented in the last section. These showed that states with compulsory job search requirements and harsh sanctions also tended to spend more on welfare-to-work programmes. These states were described as those that had 'intense conditionality'. While each of the TANF policies had effects net of one another (in model 4) it seems likely that these policy-specific effects reflect an 
TABLE 1. Impact of TANF Conditionality Policies on Days of Poor Mental Health for single low educated mothers, Coefficients.

\begin{tabular}{|c|c|c|c|c|c|c|c|c|}
\hline \multirow[b]{2}{*}{ Variables } & \multicolumn{2}{|r|}{ M1 } & \multicolumn{2}{|r|}{ M2 } & \multicolumn{2}{|r|}{ M3 } & \multicolumn{2}{|r|}{ M4 } \\
\hline & $\beta$ & $95 \%$ CI & $\beta$ & $95 \% \mathrm{CI}$ & $\beta$ & $95 \% \mathrm{CI}$ & $\beta$ & $95 \% \mathrm{CI}$ \\
\hline \multicolumn{9}{|l|}{ Individual } \\
\hline Age & 0.19 & $(0.100 .28)$ & 0.19 & $(0.100 .28)$ & 0.19 & $(0.100 .28)$ & 0.20 & $(0.110 .28)$ \\
\hline Married & -2.16 & $(-2.30-2.03)$ & -2.16 & $(-2.30-2.02)$ & -2.16 & $(-2.30-2.02)$ & -2.14 & $(-2.28-2.00)$ \\
\hline Non-White & -0.76 & $(-0.97-0.55)$ & -0.77 & $(-0.98-0.56)$ & -0.77 & $(-0.98-0.56)$ & -0.70 & $(-0.90-0.50)$ \\
\hline Single Low Ed. Mother & 0.60 & $(-0.101 .30)$ & 0.96 & $(0.501 .42)$ & 1.47 & $(1.041 .89)$ & 0.44 & $(-0.211 .08)$ \\
\hline Unemployed & 0.70 & $(0.620 .78)$ & 0.70 & $\left(\begin{array}{ll}0.62 & 0.79\end{array}\right)$ & 0.70 & $(0.620 .79)$ & 0.71 & $(0.620 .79)$ \\
\hline \multicolumn{9}{|l|}{ Contextual } \\
\hline GDP per capita & -0.27 & $(-0.38-0.16)$ & -0.21 & $(-0.32-0.12)$ & -0.22 & $(-0.32-0.12)$ & 0.11 & $(-0.160 .38)$ \\
\hline G'ment Ideology & 0.03 & $(-0.070 .12)$ & 0.04 & $(-0.050 .14)$ & 0.04 & $(-0.050 .14)$ & -0.01 & $(-0.110 .08)$ \\
\hline Citizen Ideology & -0.04 & $(-0.160 .09)$ & -0.02 & $(-0.150 .11)$ & -0.02 & $(-0.140 .11)$ & -0.10 & $(-0.330 .13)$ \\
\hline Unemployment Rate & -0.05 & $(-0.260 .15)$ & -0.02 & $(-0.200 .17)$ & -0.02 & $(-0.210 .17)$ & -0.16 & $(-0.350 .03)$ \\
\hline \multicolumn{9}{|c|}{ TANF*Single Low Ed Mother } \\
\hline Sanction (ref: V Lenient & & & & & & & & \\
\hline $\begin{array}{l}\text { V. Stringent } \\
\text { Job Search (ref: none) }\end{array}$ & 1.17 & $(0.182 .16)$ & & & & & 1.07 & $(0.092 .05)$ \\
\hline Required & & & 1.33 & $(0.452 .22)$ & & & 1.18 & $(0.292 .07)$ \\
\hline Welfare-to-work & & & & & 0.48 & $\left(\begin{array}{lll}0.13 & 0.83\end{array}\right)$ & 0.40 & $(0.040 .76)$ \\
\hline Monthly Benefit & & & & & & & 0.29 & $(-0.110 .68)$ \\
\hline $\mathrm{n}$ & & 233716 & & 233716 & & 233716 & & 233716 \\
\hline $\mathrm{N}$ & & 195 & & 195 & & 195 & & 195 \\
\hline
\end{tabular}

Notes: All models control for the mean effect of TANF policies, the Survey Wave, and for an interaction between GDP*Low Educated Single mother. Model 4 controls for $\mathrm{N}-1$ state dummy variables. All coefficients in bold have confidence intervals that differ significantly from zero. 


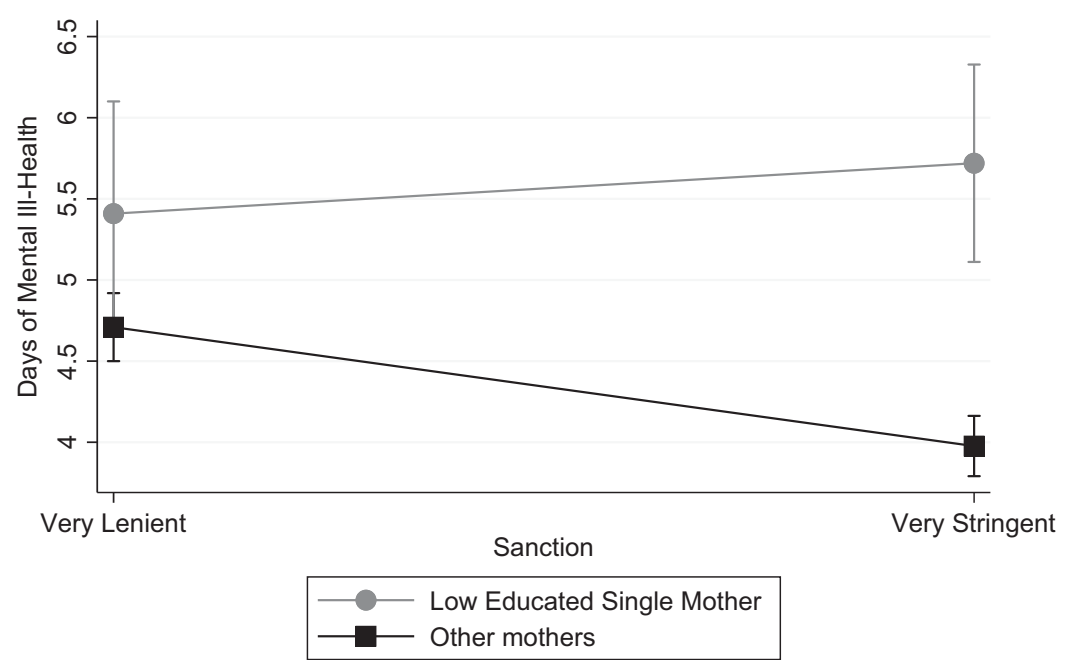

Figure 2. Impact of TANF Sanctions on Mental Health

Notes: Average Marginal Effects based on the sanctions interaction effect with low educated single mother in Table 1, Model 4. Interaction is significant at $\mathrm{p}<0.05$.

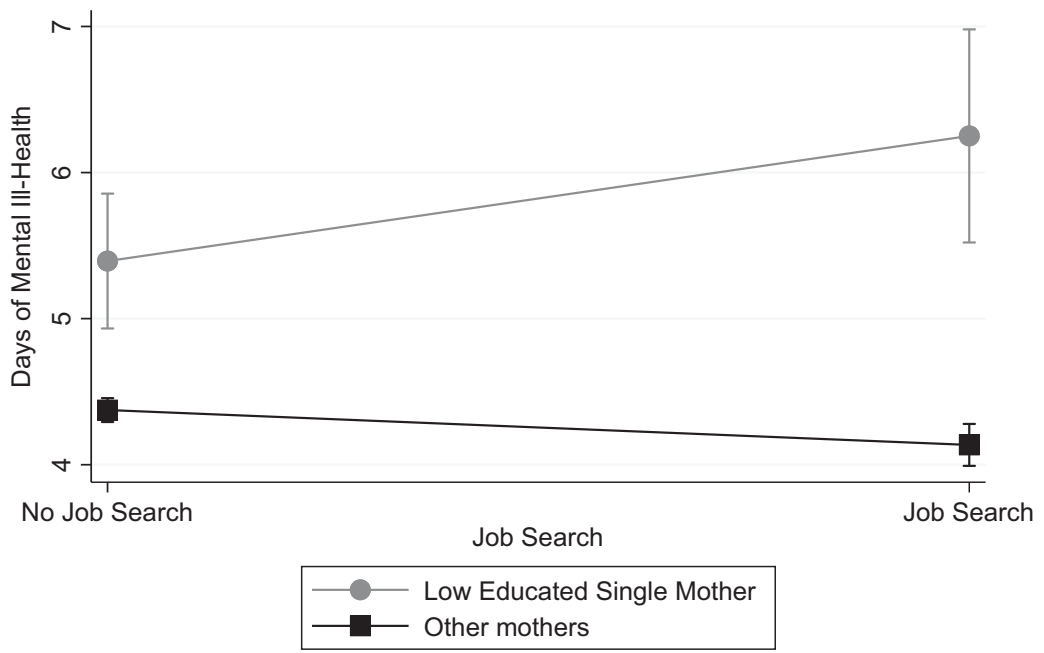

Figure 3. Impact of TANF Job Search Requirements on Mental Health

Notes: Average Marginal Effects based on the job search interaction effect with low educated single mother in Table 1, Model 4. Interaction is significant at $\mathrm{p}<0.05$.

overall impact of intense conditionality, which seems to be related with poorer mental health among target populations.

To investigate these interaction effects further, the coefficients from Table 1, model 4 are modelled as predicted probabilities. Figures 2, 3 and 4 show the 


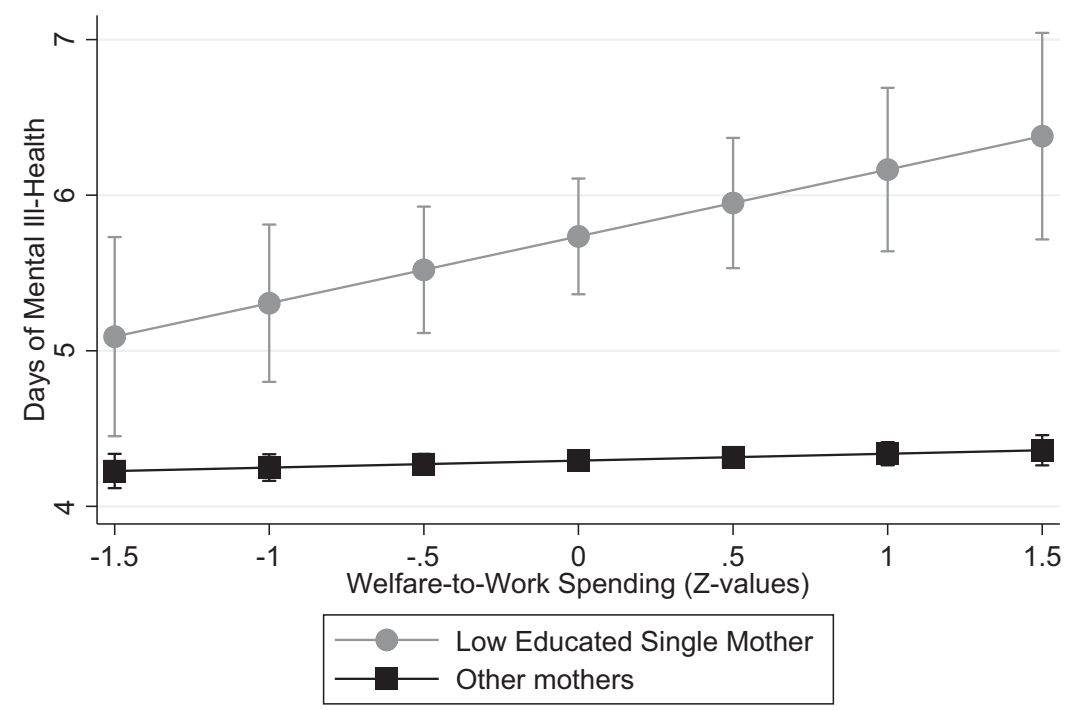

Figure 4. Impact of TANF Welfare-to-Work Policies on Mental Health

Notes: Average Marginal Effects based on the welfare-to-work interaction effect with low educated single mother in Table 1 , Model 4. Interaction is significant at $\mathrm{p}<0.05$.

effect of sanctions, job search and welfare-to-work, respectively. Reflecting the coefficients in Table 1, Figure 2 shows that the effect of sanctions is weak, while job search (Figure 3) and welfare-to-work spending (Figure 4) have a stronger negative impact on the mental health of low-educated single mothers. For both job search and welfare-to-work spending, the difference equates to approximately one day of worse mental health for low-educated single mothers between most and least stringent states. In each case confidence intervals are wide, meaning that we cannot be certain of the magnitude of the effects. Nonetheless, the overall implication of these results is that low-educated single mothers living in states with a more intense conditionality regime tend to report worse mental health than those in less stringent states.

Surprisingly, Figure 2 showed that the mental health of other mothers (the control group) was worse in states with 'very stringent' sanctions than it was in states with 'very lenient' sanctions. This difference equated to more than 1.5 days of mental ill-health. This finding is counterintuitive: we should not expect to see any effect within the control group (as is the case with job search and welfareto-work spending in Figures 3 and 4). There is no obvious explanation for the finding. It suggests that there may be some residual state-level confounding, despite the inclusion of state-level dummy variables that should remove this risk. This is a further reason to be cautious in our reading of the results and interpret the analysis in terms of the impact of the state-level conditionality regime as a whole, rather than specific elements of policy design. 


\section{Sensitivity tests}

The main sensitivity tests check the robustness of the key findings using an alternative approach to clustered data: namely, random effects. The main difference between the random and fixed effects models is that the former allows the estimation of a random error term for the level 2 data (Bryan and Jenkins, 2016). In this case, the random effects procedure allows us to estimate the proportion of variance in mental health that is explained by state or time effects.

After modelling this with the same covariates as in Table 1 (See online Appendix Table A3) the results partly confirm the earlier findings. When the TANF variables are included as cross-level interactions with low-educated single mothers, two of these variables (sanctions and job search) have a positive relationship with mental health, indicating a significantly greater detrimental effect on mental health among the treatment group. The effect of both variables was less than in Table 1. However, in each case the $\beta$ estimates for sanction/job search fell within the range of the confidence intervals in Table 1 , model 4 . We can therefore be reasonably confident that each of these variables is related to worse mental health among low-educated single mothers somewhere in the range of the confidence intervals presented in Table 1, model 4. In contrast, the effect of welfare-to-work spending was weakly negative, while it was positive in Table 1 , model 4. Given that the coefficients were markedly different in Table A3 and that the confidence intervals each suggested that the effect could be close to zero, we can be less confident of this as a true overall finding than sanctions and job search.

As another check on the findings, the treatment population group is changed to unemployed, rather than low-educated, single mothers, assuming that this group may also be at the receiving end of TANF conditionality requirements. When the analysis was re-run (see online Appendix Table A4), only job search requirements had a significant relationship to mental health among this group. What is more, this effect was not robust in the fixed effects models. One possible explanation for this surprising finding is that low-educated single mothers have more complex barriers to employment than the average unemployed single mother and that the results show the negative impact of TANF conditionality on these more disconnected groups. Further analysis lends support to this proposition. Unemployed single mothers were considerably less disadvantaged than low-educated single mothers in terms of education level, income and ethnicity ${ }^{7}$. On this basis, it is plausible that the main analysis provides a better sense of the impact of TANF conditionality for vulnerable populations. Nevertheless, these inconsistent results introduce an additional element of uncertainty, which is reflected in the concluding discussion.

Two further sensitivity tests were conducted, the results from each of which are available on request. In the first, the mental health variable was treated as a 
binary indicator and the regressions were re-fitted as logit models. This alternative operationalisation made no substantive difference to the findings, which were largely in line with those of Table 1 . The final sensitivity test examined what impact a substantial change in sampling methodology post-2011 ${ }^{8}$ may have had on the results by re-running the core analyses with only the years 2000-2010. Some minor differences were notable. However, it seems more likely that these differences were attributable to less variation in TANF variables than to any methodological difference - as, in each case, confidence intervals became wider when 2015 was excluded.

\section{Discussion}

The key findings from this article are that:

- Harsher sanctions and job search requirements are associated with wider gaps in mental health between low-educated single mothers and other mothers. There is also some evidence that higher spending on welfare-to-work is related to wider health inequalities, although this finding was less robust to sensitivity checks. While there was evidence of an effect of TANF among low-educated single mothers, TANF conditionality did not have a clear impact on the mental health of unemployed single mothers, providing further reason to be cautious in our reading of the findings.

- Nevertheless, there is reasonable evidence that the effects for low-educated single mothers are causal as they were robust to the inclusion of a range of controls and remained after controlling for unobserved state-level effects (Table 1, model 4).

- It seems plausible that the effects of these TANF policy areas represent an impact of 'intensive conditionality'. States that spent more on welfare-to-work also tended to have harsher sanctions and required job search. The results may therefore reflect the combined effects of these 'positive' and 'negative' incentive structures.

This article has offered several contributions to the existing literature. Not only is it the first study, to this author's knowledge, to explicitly link data on conditionality with mental health outcomes, it is also the first to do this using TANF policy data from 50 US states over the course of a fifteen-year period. Throughout the analysis, steps were taken to reduce the risk of confounding and other forms of bias (e.g. omitted variable). The results were also subject to various sensitivity checks and the fixed effects specification in the final models controls for all (time-invariant) between-state differences, theoretically removing the risk of omitted variable bias (at least in the case of time-invariant confounders). Hence, while we cannot discount the possibility that there were other state-level 
confounders, the modelling strategy has been rigorous in its efforts to isolate the effects of the TANF policy variables.

Yet there were still some significant limitations of the analysis. The outcome variable was a self-assessed indicator of mental health, which - although validated in one review (Pierannunzi et al., 2013) - was less ideal than other composite indicators (e.g. the Center for Epidemiological Studies Depression Scale). To lend further support to the results, it would have been preferable to examine the relationship with a wider range of health outcomes, as Basu et al. (2016) did in their analysis. Moreover, this article relied on TANF conditionality variables that were crude and provided only a broad indication of state-level policy design. Future research should scrutinise these variables further to enhance confidence that they capture the underlying concepts of interest. These conditionality variables were also limited due to the relatively small amount of variation over the fifteen-year period (i.e. most states moved towards increased conditionality). This may have introduced an element of bias into the fixed effects models and should caution us about drawing strong conclusions about the impact of TANF policy changes on mental health.

With these caveats in mind, the findings allow us to conclude cautiously that TANF conditionality matters (negatively) for mental health among recipient populations, lending support to the research hypothesis examined in this article. The exact mechanisms through which this occurs are unclear. One possibility is that conditionality may have driven disadvantaged groups away from the social security system, creating higher incidences of poverty and non-take-up among recipient populations. Several studies have found evidence for a rise in single mothers that are without cash from either employment or benefits and this has been linked with the intensification of work-related conditionality attached to receipt of TANF benefits (Blank, 2007; Turner et al., 2006). Moreover, Blank (2007) finds that among this group more than 70 per cent have a high school degree or less, lending further support to this as an explanation for the findings from this article.

Yet this is only one interpretation of the findings. An alternative explanation is that the results do not show an impact of TANF conditionality on mental health per se. They may instead reflect evidence of 'compositional effects': the impact of TANF conditionality on the characteristics of single mothers that are in and out of work. More specifically, it is plausible that the underlying trend over the fifteen-year period towards increasing conditionality may have pushed single mothers with better mental health into the labour market, while simultaneously pushing those with worse mental health out. The relationship between intensive conditionality and poorer mental health may therefore reflect the fact that mental health is poorer among low-educated mothers that have not benefited (in employment terms) from conditionality. This would suggest that conditionality has health inequalities effects. For some healthier groups, it may 
improve their mental health further by enabling them to enter work, while for others with poorer pre-existing mental health it may reinforce their exclusion by further detaching them from the labour market. Future research should seek to unpack these relationships further and would benefit from individual-level longitudinal data that enables the analysis of employment and health trajectories for sub-groups affected by conditionality.

The implication for research in this area is that more needs to be understood about the processes through which benefit conditionality impacts on health. Moreover, this needs to be explored in different institutional settings. Most of the literature reviewed in the earlier part of this article focused on the UK. Yet the impact of conditionality requirements is likely to be context-specific and the implications for health, wellbeing and social rights will be variable according to the institutional arrangements and the history and culture of a particular country. While the evidence presented in this article suggests that there may be adverse effects of conditionality on mental health in the US, this may not be the case elsewhere and further evidence is needed to investigate the sensitivity of these findings to variations in the socio-political environment.

Similarly, the policy implications of this article can only be reasonably applied in the US context. The evidence suggests that states that adopted more intensive conditionality practices had worse mental health among recipient groups. Policymakers within these states may consider closer monitoring of the health effects of conditionality practices and expanding the goals of conditionality outside of narrow economic interests such as reducing benefit caseloads. The 'Health in All Policies' framework provides one way in which policymakers could ensure that policies are monitored on health grounds (Collins and Koplan, 2009; Koivusalo, 2010). An important tool for this is Health Impact Assessments (HIAs) and it is suggested that these should be used more widely in relation to non-healthrelated policies, (echoing the arguments of Health in all Policies advocates, e.g. Collins and Koplan, 2009). Health Impact Assessments involve a series of steps to assess the social and environmental risks that policies pose to health (Suther and Sandel, 2013). A range of methods exist to evaluate HIAs and there is evidence that HIAs not only improve the health-sensitivity of policymaking, but also make policymakers more aware of the social determinants of health, thus potentially contributing to further reductions in health inequalities (Mindell et al., 2004; Veerman et al., 2005).

More broadly, this article has highlighted the scale of health inequalities in the US and the development of these inequalities over the past fifteen years (in Figure 1). The analysis suggests that TANF conditionality policies may be further cementing inequalities between advantaged and less advantaged groups through their negative impact on the mental health of low-educated single mothers. In the US, conditionality policies are disproportionately experienced by women and minority populations. These groups already have higher instances of poverty 
and are less able to access good quality work and housing. The analysis in this article implies that they may be disadvantaged further through conditionality policies, either through a direct negative impact on mental health or indirectly through the differential effects of these policies on labour market outcomes for sub-populations. This emphasises the need for policymakers to subject these policies to equality assessments and ensure that they do not contribute to the further widening of inequalities.

While this article has made a number of contributions, there has not been space to consider the impact of conditionality for other social groups (e.g. disabled people, immigrant populations). There is growing interest in the effects and appropriateness of conditionality for disabled people (Geiger, 2017). However, there is clearly the potential for researchers to investigate the impacts of conditionality across a wider range of claimant sub-populations. The article therefore ends by urging social policy analysts to continue to challenge the underlying rationale for benefit conditionality and to ensure that it is effective for all groups. This may ultimately result in more carefully-implemented conditionality policies and a wider policy approach which recognises and is responsive to the varied life-needs of individuals.

\section{Acknowledgements}

Thanks to the data collectors and distributors (Centers for Disease Control and Prevention, US Department of Health and Human Services, the Urban Institute), as well as to Dr Ben Baumberg Geiger and Professor Michael Calnan for comments on an earlier draft. Thanks are also due to the Economic and Social Research Council for funding this research. An earlier draft of this paper was presented at the European Social Policy Network (ESPAnet) Conference 2017 and thanks are due to all those that made comments. None of the above is responsible for my interpretation or any errors that remain.

\section{Supplementary material}

To view supplementary material for this article, please visit https:/doi.org/ $10.1017 /$ So047279418000363

\section{Notes}

1 For example, in 2013 nearly 40 per cent of families receiving TANF cash assistance were child-only units (i.e. headed by an adult not in receipt of TANF cash assistance).

2 Each dataset was first used in September 2016. The Welfare Rules Database was accessed from http://wrd.urban.org/wrd/Query/query.cfm and PDF files were downloaded for each of the relevant years. Data on welfare-to-work spending was downloaded from the Office of Family Assistance https://www.acf.hhs.gov/ofa, US Department of Health \& Human Services.

3 Helpful summaries of this literature are available in Grogger and Karoly (2009).

4 See page 4 of the BRFSS 2015 Data Quality Report. The BRFSS has the second best response rates of seven US-based telephone surveys (Centers for Disease Control and Prevention, (2015)). 
5 These authors found that states with more conditional TANF policies had lower caseloads but not lower unemployment rates. This finding was confirmed in separate analysis conducted by this author (available on request) with the more up-to-date TANF data.

6 These authors compare the impact on single mothers vs all other women, consistent with the research design of existing impact assessments of the PROWRA (see Basu et al., 2016: 532).

7 It was found that of the unemployed single mothers in the BRFSS, only 20 per cent were loweducated. Compared with low-educated single mothers, this group were also considerably less likely to be non-white or to have an income below $\$ 10,000$ - the threshold for deep poverty.

8 In 2011, the sampling frame was extended to include cellular telephones. While there was no evidence of changes in response rates after this year, it is plausible that such a change could have had an impact on the responses of underrepresented and disadvantaged groups such as single mothers.

\section{References}

Allison, P. (2009), Fixed effects regression models (Vol. 160), London: Sage.

Barr, B., Taylor-Robinson, D., Stuckler, D., Loopstra, R., Reeves, A. and Whitehead, M. (2016), "First, do no harm': are disability assessments associated with adverse trends in mental health? A longitudinal ecological study'. Journal of Epidemiology and Community Health, $70,4,339-345$.

Basu, S., Rehkopf, D., Siddiqi, A., Glymour, M. and Kawachi, I. (2016), 'Health Behaviors, Mental Health, and Health Care Utilization Among Single Mothers After Welfare Reforms in the 1990s', American Journal of Epidemiology, 183, 6, 531-538.

Beatty, C., Foden, M., McCarthy, L. and Reeve, K. (2015), Benefit sanctions and homelessness: a scoping report, Sheffield: Sheffield Hallam University.

Berry, W., Ringquist, E., Fording, R. and Hanson, R. (1998), 'Measuring citizen and government ideology in the American states, 1960-93', American Journal of Political Science, 42, 1, 327348.

Bitler, M., Gelbach, J. and Hoynes, H. (2005), 'Welfare reform and health', Journal of Human Resources, 40, 2, 309-334.

Blank, R. (2007), 'Improving the safety net for single mothers who face serious barriers to work', The Future of Children, 17, 2, 183-97.

Bryan, M. and Jenkins, S. (2016), 'Multilevel Modelling of Country Effects: A Cautionary Tale', European Sociological Review, 32, 1, 3-22.

Carr, E. and Chung, H. (2014), 'Employment insecurity and life satisfaction: The moderating influence of labour market policies across Europe', Journal of European Social Policy, 24, 4, 383-399.

Centers for Disease Control and Prevention (2015), Behavioral Risk Factor Surveillance System, https://www.cdc.gov/brfss/annual_data/2015/pdf/overview_2015.pdf [accessed 27.05.2018].

Clasen, J. and Clegg, D. (2007), 'Levels and levers of conditionality: measuring change within welfare states', in J. Clasen (ed.), Investigating Welfare State Change. The "Dependent Variable Problem" in Comparative Analysis, Cheltenham: Edward Elgar, 166-197.

Collins, J. and Koplan, J. (2009), 'Health impact assessment: a step toward health in all policies', Journal of American Medical Association, 302, 3, 315-317.

De Jong, G., Graefe, D., Irving, S. and Pierre, T. (2006), 'Measuring state TANF policy variations and change after reform', Social Science Quarterly, 87, 4, 755-781.

Dean, H. (2003), 'Re-conceptualising welfare-to-work for people with multiple problems and needs', Journal of Social Policy, 32, 3, 441-459.

Dwyer, P. and Wright, S. (2014), 'Universal credit, ubiquitous conditionality and its implications for social citizenship', Journal of Poverty and Social Justice, 22, 1, 27-35. 
Falk, G. (2012), 'Temporary Assistance for Needy Families (TANF): Welfare-to-Work Revisited', Washington D.C.: Congressional Research Service, http://digitalcommons. ilr.cornell.edu/key_workplace/961/ [accessed 01.10.2017].

Falk, G. (2016), The Temporary Assistance for Needy Families (TANF) Block Grant: Responses to Frequently Asked Questions. Washington D.C. Retrieved from http://digitalcommons. ilr.cornell.edu/key_workplace/1505/

Fender, L., McKernan, S. and Bernstein, J. (2002), 'Linking state TANF and related policies to outcomes: Preliminary typologies and analysis.', Washington D.C.: Department of Health and Human Services, https://www.urban.org/research/ publication/linking-state-tanf-and-related-policies-outcomes/view/full_report [accessed 01.10.2017].

Garthwaite, K., Bambra, C., Warren, J., Kasim, A. and Greig, G. (2014), 'Shifting the goalposts: a longitudinal mixed-methods study of the health of long-term Incapacity Benefit recipients during a period of substantial change to the UK social security system', Journal of Social Policy, 43, 2, 311-330.

Geiger, B. B. (2017), 'Benefits conditionality for disabled people: stylised facts from a review of international evidence and practice,' Journal of Poverty and Social Justice, 25, 2, 107128.

Grogger, J. and Karoly, L. (2009), Welfare reform: Effects of a decade of change, Cambridge, MIT: Harvard University Press.

Kilkey, M. (2017), 'Conditioning Family-life at the Intersection of Migration and Welfare: The Implications for "Brexit Families", Journal of Social Policy, 46, 4, 797-814.

Koivusalo, M. (2010), 'The state of Health in All policies (HiAP) in the European Union: potential and pitfalls', Journal of Epidemiology \& Community Health, 64, 6, 500-503.

Mead, L. (1997), The new paternalism: Supervisory approaches to poverty, Washington D.C.: Jessica Kingsley Publishers.

Meyers, M., Gornick, J. and Peck, L. (2001), 'Packaging Support for Low-Income Families: Policy Variation across the United States', Journal of Policy Analysis and Management, 20, 3, 457-483.

Mindell, J., Sheridan, L., Joffe, M., Samson-Barry, H. and Atkinson, S. (2004), 'Health impact assessment as an agent of policy change: improving the health impacts of the mayor of London's draft transport strategy', Journal of Epidemiology and Community Health, 58, 3, 169-174.

Moffatt, S., Patterson, R., Holding, E., Dennison, A., Sowden, S., Brown, J. and Lawson, S. (2015), 'A Qualitative Study of the Impact of the UK “Bedroom Tax"', Journal of Public Health, 37, 1, 1-9.

Niedzwiedz, C., Mitchell, R., Shortt, N. and Pearce, J. (2016), 'Social protection spending and inequalities in depressive symptoms across Europe', Social Psychiatry and Psychiatric Epidemiology, 51, 7, 1005-1014.

Page, S. and Larner, M. (1997), 'Introduction to the AFDC Program', The Future of Children, 7, $1,20-27$.

Pavetti, L., Derr, M. and Hesketh, H. (2003), 'Review of sanction policies and research studies', Washington D.C.: Department of Health and Human Services, https://aspe.hhs.gov/system/files/pdf/72646/full-report.pdf [accessed 30.09.2017].

Pierannunzi, C., Hu, S. and Balluz, L. (2013), 'A systematic review of publications assessing reliability and validity of the Behavioral Risk Factor Surveillance System (BRFSS) 20042011', BMC Medical Research Methodology, 13, 1, 1.

Rector, R. and Youssef, S. (1999), The determinants of welfare caseload decline, Washington, DC: Heritage Foundation.

Reeves, A. and Loopstra, R. (2016), 'Set up to fail'? How welfare conditionality undermines citizenship for vulnerable groups', Social Policy and Society, 16, 2, 327-338.

Shutes, I. (2016), 'Work-related conditionality and the access to social benefits of national citizens, EU and Non-EU citizens', Journal of Social Policy, 45, 4, 691-707. 
Suther, E. and Sandel, M. (2013), 'Health impact assessments', Rhode Island Medical Journal, 96, 27-30.

Turner, L., Danziger, S. and Seefeldt, K. (2006), 'Failing the transition from welfare to work: Women chronically disconnected from employment and cash welfare', Social Science Quarterly, 87, 2, 227-249.

Veerman, J., Barendregt, J. and Mackenbach, J. (2005), 'Quantitative health impact assessment: current practice and future directions', Journal of Epidemiology \& Community Health, 59, 5, 361-370.

Wulfgramm, M. (2011), 'Can activating labour market offset the detrimental life satisfaction effect of unemployment?', Socio-Economic Review, 9, 3, 477-501. 